\title{
MECHANISMS OF THE REVERSIBLE ELECTROCHEMICAL INSERTION OF LITHIUM OCCURRING WITH NCIMS (NANO-CRYSTALLITE- INSERTION-MATERIALS)
}

\author{
S.D. HAN, N. TREUIL, G. CAMPET, ${ }^{*}$ J. PORTIER, C. DELMAS \\ Laboratoire de Chimie du Solide du CNRS, 351 cours de la Libération-33405 Talence-France \\ J.C. LASSÈGUES \\ Laboratoire de Spectroscopie Moléculaire et Cristalline du CNRS, 351 cours de la Libération-33405 \\ Talence-France \\ A. PIERRE \\ Department of Mining-Metallurgical and Petroleum Engineering, University of Alberta- \\ Edmonton-Alberta, T6G-2G6-Canada
}

(Received September 7, 1993; in final form November 8, 1993)

\begin{abstract}
A new family of insertion-compound electrodes, so called $\mathrm{NCIM}_{\mathrm{s}}$ (Nano-Crystallite-Insertion-Materials), has been proposed: the major requirement is that the electrode materials have to be polycrystalline with a crystallite and particle size as small as possible (the accepted definition being that many crystallites make a particle). Indeed, by minimizing the size of the crystallites, the formation of defects bonds is favored, particularly at the crystallite surface, acting as reversible (de)grafting sites of $\mathrm{Li}^{+}$. Also, the cation-anion bonding is weakened not only in the grain boundary region but also within the crystallite close to its surface: then the electrochemical insertion of $\mathrm{Li}^{+}$takes place through easy bonding rearrangements.
\end{abstract}

\section{INTRODUCTION}

In the last 20 years, much attention has been focused on $\mathrm{A}_{\mathrm{x}} \mathrm{MO}_{2}$-type intercalation compounds $(\mathrm{A}=\mathrm{Li}, \mathrm{Na}$ and $\mathrm{M}=\mathrm{Co}, \mathrm{Ni}, \mathrm{Mn}$. . .), which are used as positive electrodes in reversible alkali electrochemical cells (see for example refs. 1). However, a very long-term cyclability (i.e., over $10^{3}$ cycles) might be hardly achievable, particularly for corresponding electrodes having a large grain size, probably because the $\mathrm{Li}^{+}$(de)intercalation process slightly perturbs the host lattice.

Some of us have patented, a few years ago, a new strategy and related experiments that have enabled us to put forward a rather new family of insertioncompound electrodes able to sustain long-term $\mathrm{Li}^{+}$electrochemical cyclability ${ }^{2}$. The major requirement is that the electrode materials are polycrystalline with a crystallite and particule sizes as small as possible. Therefore, we later called the polycrystalline electrode materials $\mathrm{NCIM}_{\mathrm{s}}$ (for nano-crystallite-insertion material $)^{3.4}$.

* Author for correspondence. 
TABLE I

Some nanocrystallite insertion materials (NCIMs)

\begin{tabular}{|c|c|c|c|}
\hline Sample & Class & $\begin{array}{l}\text { Average grain } \\
\text { size }(\AA)\end{array}$ & $\begin{array}{l}\text { Insertion rate } x \text { (measured in } \\
\mathrm{LiClO}_{4}(\text { p.c. }) \\
1.5 \mathrm{~V} \leq \mathrm{V}(\mathrm{Li}) \leq 3.5 \mathrm{~V})\end{array}$ \\
\hline $\mathrm{Li}_{\mathrm{x}} \mathrm{SrTiO}_{3}$ & D & 80 & $0 \leq x \leq 0.3$ \\
\hline $\mathrm{Li}_{\mathrm{x}} \mathrm{CrO}_{2}$ & I & 30 & $0 \leq x \leq 1$ \\
\hline $\mathrm{Li}_{\mathrm{x}} \mathrm{Mn}_{2} \mathrm{O}_{3}$ & I & 50 & $0 \leqslant x \leqslant 2$ \\
\hline $\mathrm{Li}_{x} \mathrm{Fe}_{2} \mathrm{O}_{3}$ & D & 150 & $0 \lesssim x \leqslant 0.5$ \\
\hline $\mathrm{Li}_{x} \mathrm{NiO}_{2}$ & I & 60 & $1 \leq x \leq 2$ \\
\hline $\mathrm{Li}_{\mathrm{x}} \mathrm{CuO}_{2}$ & I & 50 & $1 \leqslant x \leqslant 2$ \\
\hline $\mathrm{Li}_{\mathbf{x}} \mathrm{WO}_{3}$ & D & 40 & $0 \leq x \leq 2$ \\
\hline
\end{tabular}

Table I gives important examples related to mixed-valency metal oxides ${ }^{2.5}$. For clarity, the examples listed in Table I have been divided into two classes, I and D, according to whether the resistivity tends to increase (class I) or to decrease (class D) upon the electrochemical $\mathrm{Li}^{+}$insertion process.

Rather similar considerations were reported by Barloux et al. and concern the spinel $\mathrm{LiMn}_{2} \mathrm{O}_{4}{ }^{6}$. Also apparently related to that, Kumagai et al. ${ }^{7}$ have reported that the positive electrode $\mathrm{MnO}_{2} \cdot \mathrm{yV}_{2} \mathrm{O}_{5}$ was formed by incorporation of $\mathrm{V}_{2} \mathrm{O}_{5}$ into $\mathrm{MnO}_{2}$ matrices and the crystallinity of the oxide decreased with increase in $\mathrm{V}_{2} \mathrm{O}_{5}$ content incorporated. They have shown that the amount of $\mathrm{Li}^{+}$ions that can be reversibly electrochemically (de)insered increased with increasing y value, i.e., with decrease in the crystallinity; it reached about $1 \mathrm{Li}^{+}$per mole of the oxide with $y$ $=0.6^{7}$.

In this paper, the framework of the model accounting for the reversible electrochemical $\mathrm{Li}^{+}$insertion occurring in the $\mathrm{NCIM}_{\mathrm{s}}$ is presented. We also show, for the first time, that the model accounts for the evolution of the open circuit voltage of the electrodes, vs the fraction, $x$, of the alkali.

\section{MECHANISMS OF THE REVERSIBLE ELECTROCHEMICAL INSERTION OF LITHIUM OCCURING WITH NCIM}

First of all, by minimizing the size of the crystallites we tend to:

(i) favor the formation of defect bonds, particularly at the crystallite surface (of its vicinity), such as anion adjacent to cation vacancies: these defects act as reversible (de)grafting sites for $\mathrm{Li}^{+}$.

(ii) weaken the cation-anion bonding not only on the grain boundary region but also within the grain close to its surface: then the electrochemical insertion of $\mathrm{Li}^{+}$occurs through easy bonding rearrangements ${ }^{3}$.

That is depicted below for $\mathrm{SrTiO}_{3}$-NCIM, taken as a non-limiting but illustrative example. First of all, Fig. 1 illustrates the electron conduction via $[\mathrm{Ti}: 3 \mathrm{~d}]_{\text {sub }}$ or $[\mathrm{Ti}: 3 \mathrm{~d}]_{\mathrm{bw}}$ energy states.

- $[\mathrm{Ti}: 3 \mathrm{~d}]_{\text {sub }}$ represents deep subband-gap energy states arising from cation defects adjacent to an anion vacancy. They are lowered below the $\pi^{*}$ conduction 


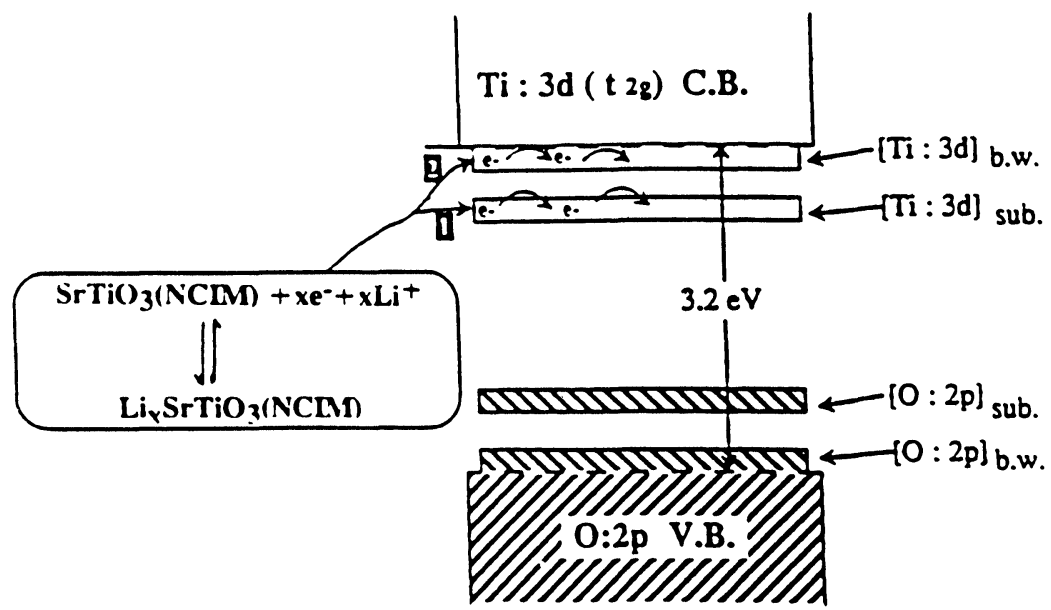

FIGURE 1 Simplified band energy scheme of $\mathrm{SrTiO}_{3}$-NCIM.

band of $\mathrm{Ti}^{4+}: 3 \mathrm{~d}^{0}\left(\mathrm{t}_{2 \mathrm{~g}}\right)$ parentage. Conversely, anion defects adjacent to cation vacancies occur. They introduce acceptor states $[\mathrm{O}: 2 \mathrm{p}]_{\text {sub }}$ arising from the $\mathrm{O}^{2-}: 2 \mathrm{p}^{6}$ valence band. According to the model, the latter defects act as reversible (de)grafting sites for $\mathrm{Li}^{+}$, (see (i)).

- the $[\mathrm{Ti}: 3 \mathrm{~d}]_{\mathrm{bw}}$ and $[\mathrm{O}: 2 \mathrm{p}]_{\mathrm{bw}}$ energy states originate from Ti-O bond weakening. This bond weakening induces $\mathrm{Li}^{+}$(de)insertion as mentioned above (see (ii)).

We will see, now, that the model accounts for the differences observed between the open-circuit voltage (OCV) vs $\mathrm{x}$ (the fraction of the alkali) curves related to polycrystalline electrodes having different sizes of crystallites. For sake of simplicity, such a behavior is illustrated only for two n-type electrodes $\mathrm{Li}_{\mathrm{x}} \mathrm{SnO}_{2}$ and $\mathrm{Li}_{\mathrm{x}} \mathrm{WO}_{3}$ (Fig. 2a, b).

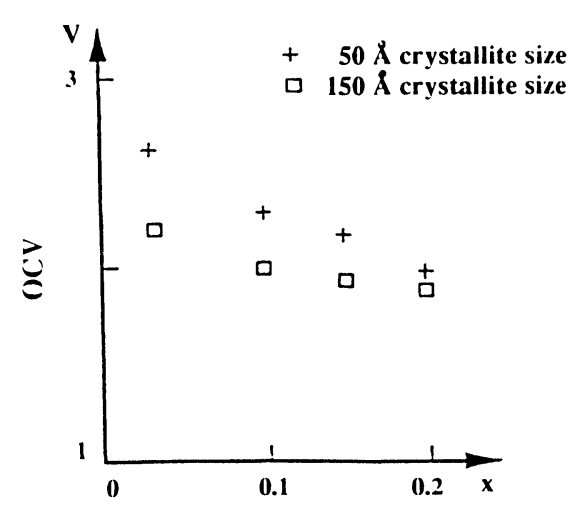

(a)

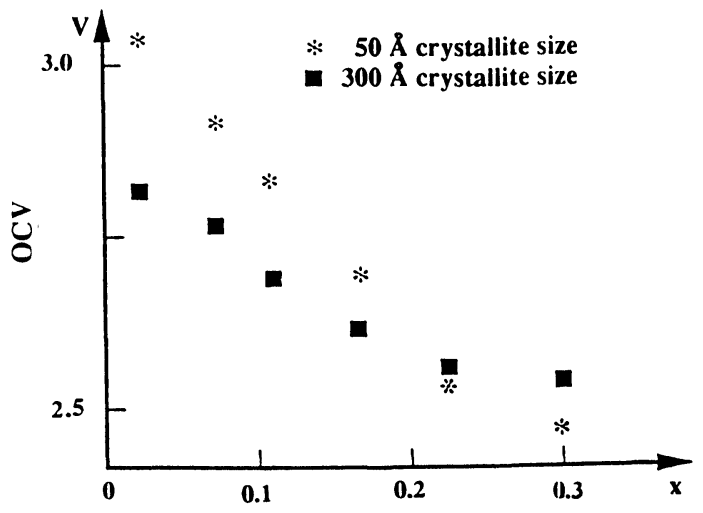

(b)

FIGURE 2 Equilibrium OCVs vs $x$ for some $\mathrm{Li} / \mathrm{LiCF}_{3} \mathrm{SO}_{3} / \mathrm{NCIMs}\left(\mathrm{a}: \mathrm{Li}_{\mathrm{x}} \mathrm{SnO}_{2} ; \mathrm{b}: \mathrm{Li}_{\mathrm{x}} \mathrm{WO}_{3}\right)$. 
The concentration of the "sub" and b.w." states increases as the crystallite size is reduced. This obviously causes, only for the lower $\boldsymbol{x}$ values, a "pushing" of the Fermi-energy $\left(E_{F}\right)$ and thereby of OCV towards "cathodic" values. Indeed, for the lower $\mathrm{x}$ values, the $\mathrm{OCV}$ are higher for the electrodes having the smallest crystallite size (Fig. 2a and $2 b$ for $x \leq 0.15$ ).

For higher $\mathrm{x}$ values $(\mathrm{x}>>0.15)$ and when the inside-crystallite structure is well adapted for the reversible intercalation of lithium as it occurs for $\mathrm{Li}_{\mathrm{x}} \mathrm{WO}_{3}$, an inversion of the OCV is observed (Fig. 2b): indeed for $x>>0.15$ all the subband gap energy states $\left[\mathrm{W}^{6+}: 5 \mathrm{~d}^{0}\right]_{\text {sub }}$ and $\left[\mathrm{W}^{6+} 5 \mathrm{~d}^{0}\right]_{\mathrm{bw}}$ (the "twin states" of $\left[\mathrm{Ti}^{4+}: 3 \mathrm{~d}^{0}\right]_{\text {sub }}$ and b.w. reported in Fig. 1) are filled with electrons. Therefore, the lithium intercalation within the nanocrystallites can now take place; it is accompanied with a "delocalization" of the injected electrons in the conduction band. On the other hand, it is well established that the band-energy width increases as the crystallite size decreases [8]; therefore the $\mathrm{WO}_{3}$ electrodes having the smallest crystallite size have their conduction-band edge shifted towards "anodic" values: this causes a "decrease" of $E_{F}$, and thereby of $\mathrm{OCV}$, towards "anodic" values (as it is illustrated on Fig. $2 b$ for $x>>0.15$ ).

\section{THE NCIM HAVE BEEN INVESTIGATED IN DIFFERENT FORMS: EITHER POWDERED ELECTRODES (A) OR COMPOSITE ELECTRODES (B) OR THIN FILM ELECTRODES (C).}

\section{Powdered Electrodes or Composite Electrodes}

They can be efficiently used as positive electrodes for rechargeable lithium batteries of high energy density. Figure 3 shows the charge-discharge curves for powdered and composite electrodes.

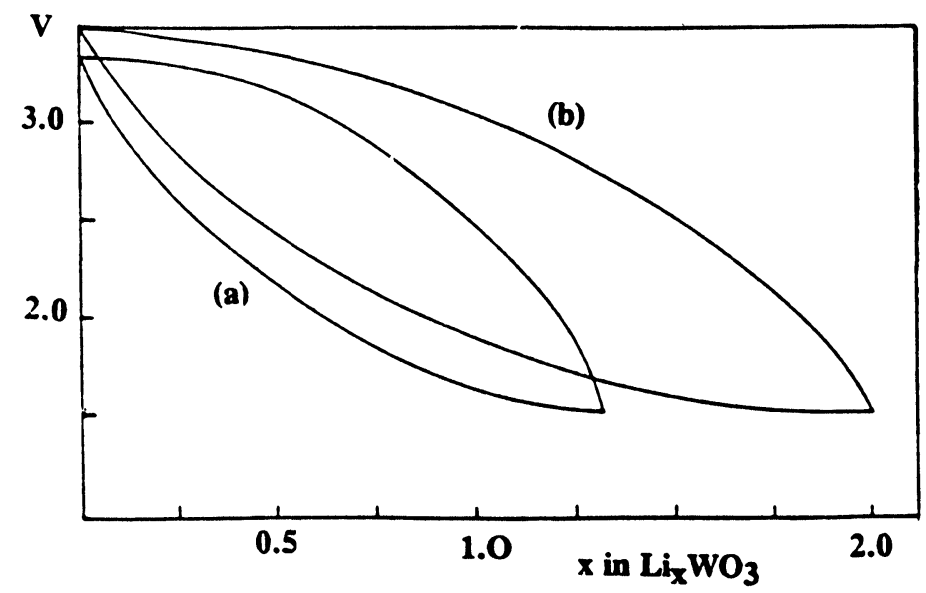

FIGURE 3 Charge-discharge curves of: (a) $\mathrm{Li} / \mathrm{LiClO}_{+}-$p.c. $/ \mathrm{WO}_{3}-\mathrm{NCIM}\left(50 \AA\right.$ size), (b) $\mathrm{Li} / \mathrm{LiClO}_{4}$ p.c./"soft" composite electrode consisting of $\mathrm{WO}_{3}-\mathrm{NCIM}(50 \AA \AA$ size $)$ dispersed in conductive polymer. 


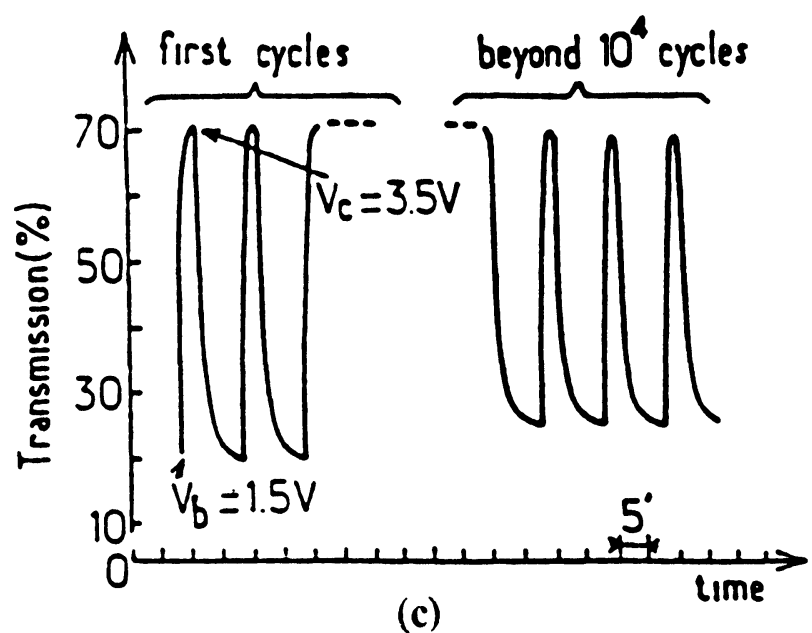

FIGURE 4 Transmission $(\lambda=550 \mathrm{~nm}$ ) vs time for repeated coloring and bleaching cycles with the $\operatorname{NCIM}(50 \AA)$ counter electrodes $\mathrm{Li}_{2-x} \mathrm{NiO}_{2}$ (c). The $\mathrm{Li}^{+}$insertion rate, $\mathrm{x}$, varies within 0 and 1 . The coloring and bleaching potentials $\mathrm{Vc}$ and $\mathrm{Vb}$ are measured vs $\mathrm{Li}$ in $\mathrm{LiClO}_{4}$ p.c. electrolyte.

\section{Thin Film Electrodes}

They can be efficiently used either as positive electrodes for thin-film rechargeable batteries of high energy density or as counter electrodes for electrochromic windows. Transmission vs time for repeated coloring and bleaching cycles is shown in Figure 4.

\section{REFERENCES}

1. J. Rouxel, in F. Levy (ed.), Physics and Chemistry of Layered Materials, vol. VI, Reidel, Dordrecht, 1979.

K: Mizushima, P.C. Jones, P.J. Wiseman and J.B. Goodenough, Solid State Ion., 3-4 (1981) 171.

C. Delmas, J. Braconnier, A. Maazaz and P. Hagenmuller, Rev. Chem. Miner., 19 (1982) 343.

J. Molenda, Solid State Ion., 21 (1986) 263.

S. Miyazaki, S. Kikkawa and M. Koizumi, Synth. Met., 6 (1983) 211.

2. J.P. Couput, G. Campet, J.M. Chabagno, M. Bourrel, D. Muller, R. Garrié, C. Delmas, B. Morel, J. Portier and J. Salardenne, Int. Appl. Publ. under PCT. Int. Pat. Class GO2F 1701, FO1 G9/ 00, C 23C 14/34, WO 91/01510, 1989.

3. N. Treuil, G. Campet, unpublished results: DEA report of N. Treuil. Bordeaux (1993).

4. G. Campet, S.D. Han, N. Treuil, MCR Shastry, J. Portier, C. Delmas, J.C. Lassègues, Mat. Sciences and Eng. B (submitted for publication).

5. B. Morel, Doctoral thesis, University of Bordeaux I (1991).

6. P. Barloux, J.M. Tarascon and F.K. Shokoohi, J. Solid State Chem. 94 (1991) 185.

7. N. Kumagai, S. Tanifuji, T. Fujiwara and K. Tanno, Electrochịim. Acta, 37(6) (1992) 1039.

8. P.E. Lippens and M. Lanoo, Physical Review B, 39 (1989) 15. 

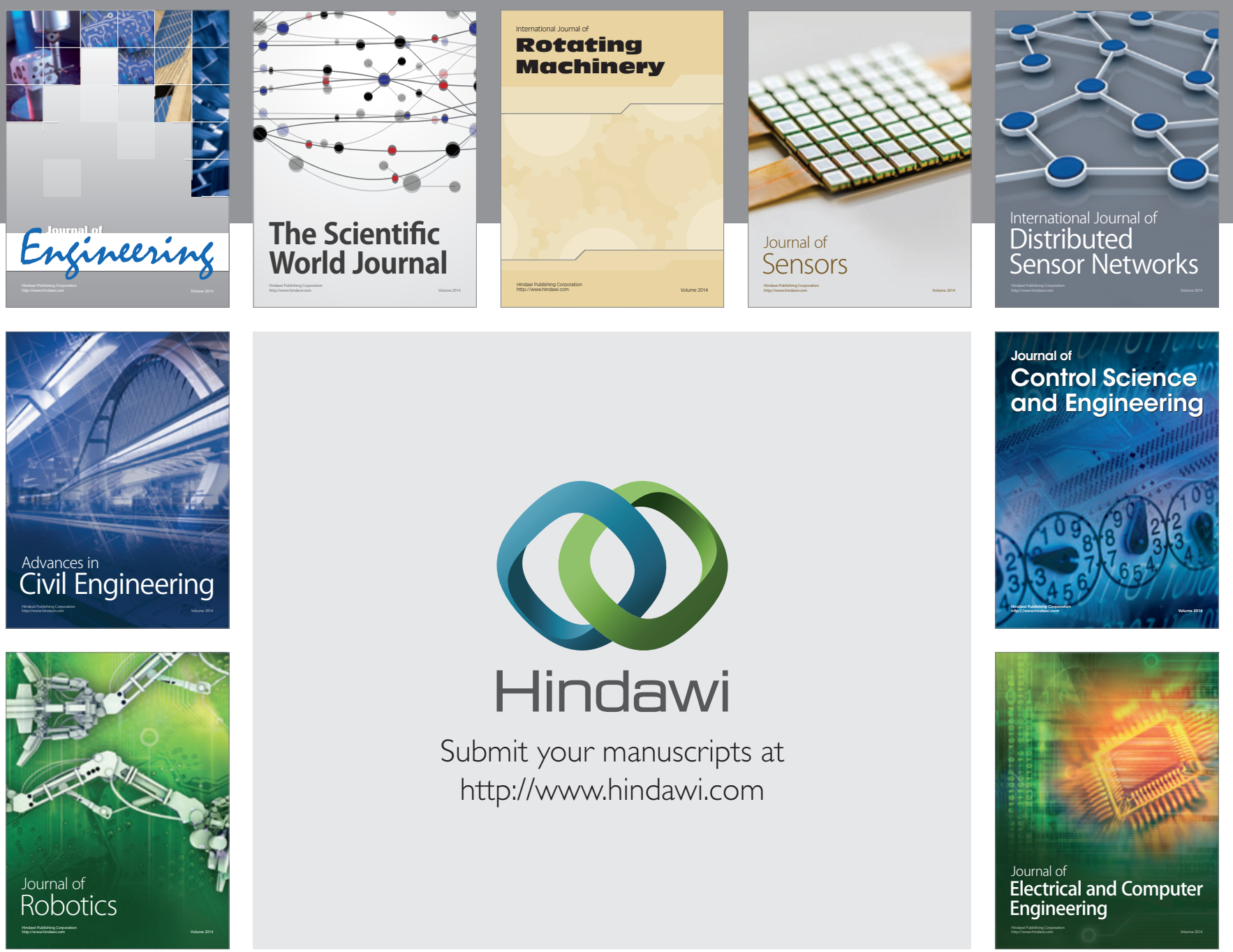

Submit your manuscripts at

http://www.hindawi.com
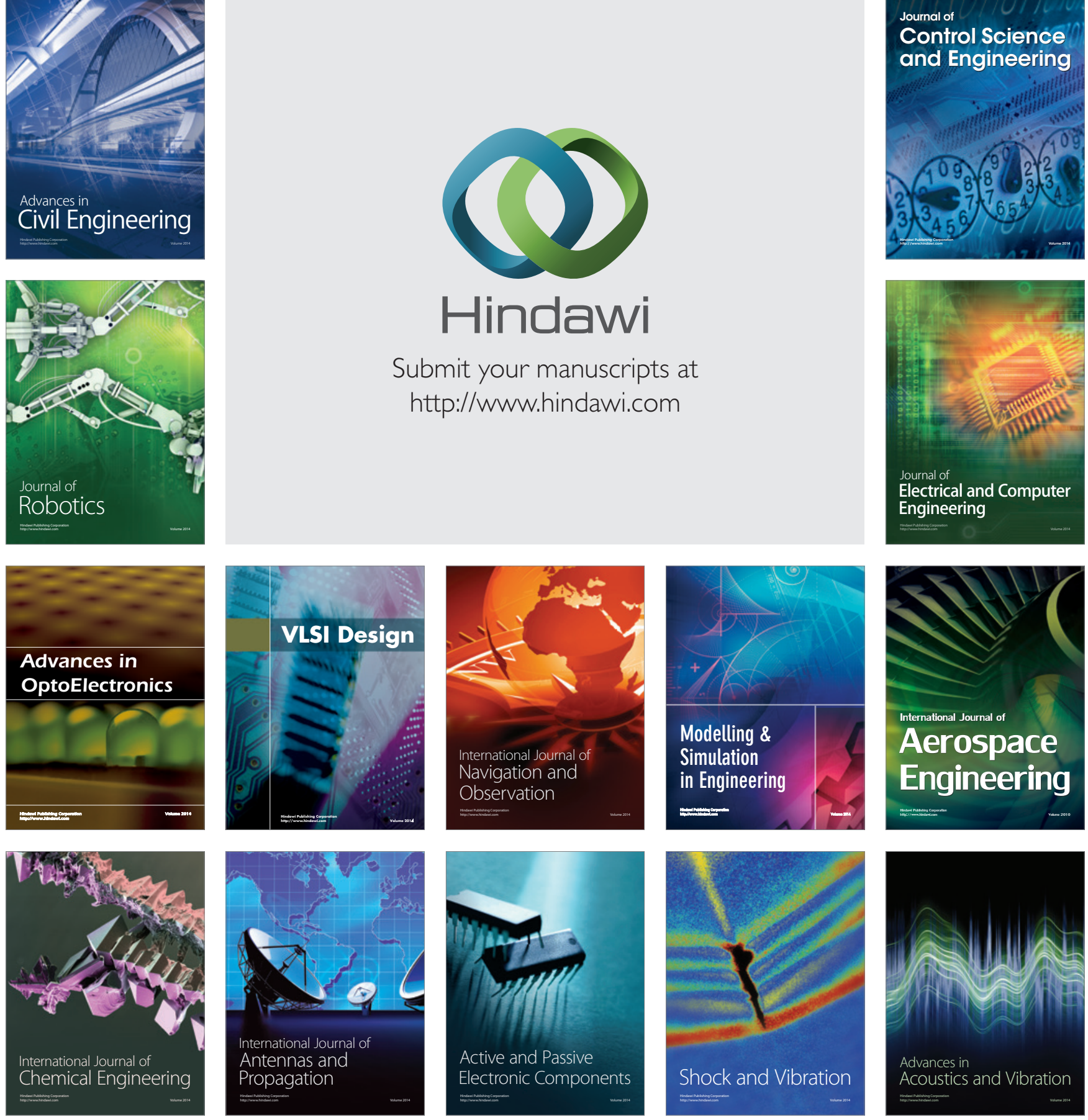